\title{
Ultrasonographic Assessment of Embryonic Mortality in Cows
}

\author{
Pinki Rani $^{1 *}$, R.K. Chandolia ${ }^{1}$, Ravi Dutt ${ }^{1}$, Nitin Soni ${ }^{1}$, S.S. Dhaka ${ }^{2}$, \\ Sandeep Kumar ${ }^{1}$, A.K. Pandey ${ }^{3}$ and Gyan Singh ${ }^{3}$
}

${ }^{1}$ Department of Veterinary Gynaecology and Obstetrics, ${ }^{2}$ Department of Animal Genetics and Breeding, ${ }^{3}$ Veterinary Clinical Complex, LUVAS, Hisar -125 004, Haryana, India

*Corresponding author

\section{A B S T R A C T}

Keywords

Cow, Cytobrush,

Embryonic mortality,

Heartbeat,

Ultrasonographic

scanning

Article Info

Accepted:

02 May 2018

Available Online:

10 June 2018
The present study was carried out with the objective to detect embryonic mortality in a total of 142 cows inseminated at spontaneous estrus. The ultrasonographic scanning with trans-rectal probe using frequency of $7.0 \mathrm{MHz}$ was carried out on day 28 to confirm pregnancy and re-examination on day 45 to assess the incidence of embryonic mortality under farm conditions. Out of 53 animals which exhibited non-return to estrus, 51 animals were having viable embryo with heart beat on day 45 post-insemination. Thus, incidence of embryonic mortality in the current investigation recorded was $3.77 \%(2 / 53)$. The embryonic heart beat on day 28 and 45 was recorded to be $177.94 \pm 2.16$ and $190.28 \pm 2.77$ beats per minute. The cytobrush sampling was also carried out on day 45 in two animals that suffered from embryonic mortality to rule out the specific or non-specific infectious cause of embryonic mortality, if any and no microbial cause of embryonic mortality was observed.

\section{Introduction}

Embryonic mortality (EM) is generally defined as loss of the conceptus which occurs during the first 45 days of pregnancy, which is the period from conception to completion of differentiation (Committee on Reproductive Nomenclature, 1972). Approximately $30 \%$ of pregnancies are lost in the form of embryonic demise and this increases the successive calving interval thereby ultimately affecting the success of reproductive programs in dairy cows (Chaudhary and Purohit, 2012). Early embryonic mortality is a major source of economic loss with mortality rate upto $40 \%$ in animal production through repeat breeding and increased cost of artificial insemination (Sareen and Diskin, 1986; Zavy, 1994; Bajaj, 2001) cost of treatment, extended calving intervals and prolonged dry period resulting in reduced milk production (Roche et al., 1981) and reduced net calf crop (Maurer and Chenault, 1983). The cost of losses to farmers due to embryonic mortalities has been estimated as high as 250 million per year in UK (Hensela et al., 1976). Although, it is clearly not possible to extrapolate these figures to the whole world as national 
agricultural economics vary so widely, it can be seen that global cost of embryonic mortality in a total cattle population (Bos taurus and Bos indicus) of approximately $1.28 \times 10^{12}$ (FAO, 1994) is a large amount clearly justifying the relatively modest sums invested in research into its causes. Earlier, it was believed that the bovine conceptus gets reabsorbed, but trans-rectal ultrasound examination had demonstrated that the conceptus and its breakdown products apparently are eliminated by expulsion through the cervix, which either goes unnoticed or appear as a vulvar discharge of clear mucus (Kastelic et al., 1991).

Also some infectious and hormonal factors may participate in embryonic mortalities (Companile et al., 2007; Bajaj and Sharma, 2011).

Some viral, bacterial, protozoal and possibly mycoplasmal infections can result in embryonic death, indirectly by systemic effects via septicemia, viremia or toxemia in the dam or directly by affecting the embryo or contaminating uterine environment. EM caused by systemic pathogens is usually related to fever during the infection. High fever present in the first stage of pregnancy can lead to early embryonic death as a result of denaturation of embryonic proteins. Luteal insufficiency during post insemination period is considered as one of the predisposing factor leading to embryonic mortality (Diskin and Moris, 2008).

Embryonic mortality can be diagnosed by using a variety of techniques including measurement of milk progesterone concentration (Stronge et al., 2005) or pregnancy specific proteins (Prvanovic et al., 2009), trans-rectal ultrasonography (Romano et al., 2006) and trans-rectal palpation (Balhara et al., 2013; Bekele et al., 2016). Since the widespread application of real time ultrasonography as a research tool to study bovine reproduction represents a technological breakthrough that has revolutionized our understanding of reproductive biology in cattle (Fricke, 2002). But, with the advancement of real time ultrasound in modern times, the aforesaid technology can be implemented at an organized farm to determine the incidence of embryonic mortality. Few economic analyses on the use of ultrasonography for reproductive management of dairy cattle have been published to date.

Ultrasound has previously been reported to be an economically profitable reproductive management strategy for dairy farms (Beal $e t$ al., 1992). Moreover, the information regarding ovarian and uterine status during early pregnancy and after early embryonic death is very less in literature.

Secondly, under Indian field and farm conditions the incidence of early embryonic mortality has not been reported so far. With the advent of real time ultrasound in modern times, the aforesaid technology can be implemented at an organized farm to detect early pregnancy and embryonic mortalities from day 28 to 45 post-insemination.

\section{Materials and Methods}

\section{Location of the study}

The present study was carried out in the herd of Sahiwal and Hardhenu cows at the Cattle farm situated at North Latitude (NL) $29^{0} 8^{\prime}$ 39"; East Longitude (EL) $75^{\circ}$ 41' 44", Department of Animal Genetics and Breeding, Lala Lajpat Rai University of Veterinary and Animal Sciences, Hisar (Haryana) between July to December, 2017. The temperature and relative humidity during the study period ranged between 17.8 to $31.2^{\circ} \mathrm{C}$ and 49.48 to $88.45 \%$ respectively. 


\section{Experimental animals and management}

From the entire herd, a total of 142 cows were selected for the study. Out of which Sahiwal and Hardehenu were 29 and 113, respectively. Animals selected for experiments were in average to good body condition, the body condition score (BCS) ranged over 2.5 on a scale from 1 to 5 . All animals were free from any kind of anatomical and reproductive disorders and clinically healthy. Estrus detection was done by parading a teaser bull daily during morning and evening. The age group and body weight of the animals ranged between 2.5 to11 years and 300 to $500 \mathrm{~kg}$, respectively. Cows selected for the experiment were housed in half walled pucca sheds with asbestos sheet roof. Cows were stall-fed with adequate quantity of green fodder and wheatbhoosa. Concentrate feed, supplemented with mineral mixture and common salt, was also provided. The feed requirement was adjusted keeping in view milk yield of individual cows. Drinking water was provided $a d$. lib. Animals were well protected from inclement weather.

\section{Artificial insemination}

All the 142 animals detected at spontaneous estrus were subjected to artificial insemination at the end of standing heat according to $\mathrm{AM} / \mathrm{PM}$ rule i.e. if animal was detected at estrus in the morning, the artificial insemination (AI) was performed in the evening on the same day and if the animal was detected in the estrus in the evening, AI was performed in the next morning. All the animals were inseminated with elite quality frozen semen after proper thawing.

\section{Ultrasonographic scanning for pregnancy}

The animals with non-return to estrus were subjected to ultrasonographic examinations using real time B-mode ultrasound scanner (SONPSCAPE S6/S6Pro/S6BW Portable
Digital Color Doppler Ultrasound System) equipped with a linear array trans-rectal multifrequency transducer using frequency of 7.0 $\mathrm{MHz}$ at day 28 post-insemination. After proper restraining of the animal in a chute, without use of any tranquilizing agents, faecal material was removed from the rectum. Ultrasound jelly was applied over the surface of transducer before its insertion into the rectum. The location of $\mathrm{CL}$ on ovary was determined by rectal probe through positioning at close proximity to the dorsal surface of the uterine horn. After initial orientation, ipsilateral uterine horn was scanned over its dorsal surface and then on lateral surface for signs of pregnancy. Positive diagnosis of pregnancy was based on the presence of a non-echogenic round area of varying size in the lumen of an echogenic uterine horn representing the fluid filled allantoic cavity termed as embryonic vesicle (Pierson and Ginther, 1984; Pieterse et al., 1990). The embryonic heart beats were used as the main criteria to assess the viability of the embryo and the heart beat was observed within the cranial, cone-shaped thorax of the embryo. This was treated as the positive sign of confirmatory pregnancy (Singh et al., 2018). The second ultrasonographic reading was taken on day 45 post-insemination for detection of embryonic mortality by observing the changes in the uterine content and loss of fetal fluid from the uterus previously diagnosed gravid on day 28 post-insemination. The images of embryo in gravid uterus were frozen and saved.

\section{Diagnosis of early embryonic mortality through cytobrush technique}

The animals which exhibited embryonic mortality were subjected to cytobrush technique to assess the microbial nature of the etiology, if any. First of all, cleaning the perineal portion of properly restrained animal was done and the vulva was cleansed with wet 
paper towels, by following recto-vaginal method the left hand was inserted to empty the rectum and to palpate the genitalia properly. Loading of sterile cytobrush was done under aseptic environmental conditions. Then, the sterile loaded cytobrush assembly (especially fabricated for bovine containing intrauterine catheter and a stilette attached with cytobrush) (Fig. 1) was introduced into uterus placed in a sanitary plastic sleeve for protection from vaginal contamination with right hand. The instrument was advanced through the cervix into the base of the larger horn, at which point the plunger was pushed far enough to expose the cytobrush tip to endometrial surface. Slowly rotated one half to one full turn in a clockwise direction while in contact with the uterine wall. The cytobrush was retracted back into the stainless steel tube prior to removal from the uterus. Immediately after removal from reproductive tract, the cytobrush was smeared on clean sterilized glass slides. The slide was fixed in methanol for one minute and stained with Field's stain with slight modification (3-4 dips in Solution A and B). The slide was observed first under microscope under 100X and then under oil immersion (1000X magnification) by counting 100 cells to determine the percentage of polymorphonuclear cells. Each slide was read by two persons and the average of the readings was considered. After that the cytobrush tip containing samples were immediately dipped into sterile tubes containing the brain heart infusion (BHI) broth and transported to the laboratory within 1 hour and kept in an incubator for 24 hours at $37^{\circ} \mathrm{C}$. The BHI broth was then checked for the turbidity and using a sterilized loop the broth culture was streaked onto BHI and selective media viz. 5\% defibrinated sheep blood agar plate and MacConkey lactose agar plate and incubated aerobically at $37^{\circ} \mathrm{C}$ for $16-18$ hours. The sample was also inoculated on Blood Agar, MacConkey's lactose agar (MLA) and Sabouraud Dextrose Agar (SDA). The plates were incubated at $37^{\circ} \mathrm{C}$ for 48 hours. Also these samples are scanned for presence of Trichomonas and Campylobacter fetus infection in the laboratory of Animal Biotechnology department.

\section{Results and Discussion}

\section{Early pregnancy diagnosis on day 28}

All the 142 cows at spontaneous estrus were subjected to artificial insemination. The animals which showed failure to exhibit estrus (53 animals) were subjected to trans-rectal real time B-mode ultrasonography using frequency of $7.0 \mathrm{MHz}$ of trans-rectal probe. The uterus was located well and was visualized through all the sides with transducer in all the animals. Thus, the chances of missing the embryonic vesicle were negligible. Positive diagnosis of pregnancy was based on the presence of a non-echogenic round area of varying size in the lumen of an echogenic uterine horn representing the fluid filled allantoic cavity termed as embryonic vesicle. In the nonechoic vesicle, echoic conceptus is shown in Figure $2 \mathrm{a}$ and $2 \mathrm{~b}$ for Sahiwal and Hardhenu, respectively. The embryonic heart beats were used as the main criteria to assess the viability of the embryo and the heart beat was observed within the cranial, cone-shaped thorax of the embryo and this was treated as the positive sign of confirmatory pregnancy (Fig. 3). Thus, on day 28 post-insemination pregnancy was confirmed with $100 \%$ accuracy. The heart beat was calculated as the distance between two alternate peaks by using inbuilt Doppler system of machine. Breed wise data of embryonic heart beat in Sahiwal $(n=9)$ and Hardhenu ( $n=9)$ was recorded (Table 1) and the images of embryo in gravid uterus were frozen and saved.

Thus, ultrasonography facilitated diagnosis of all non-pregnant animals at an early stage (day 28 post-insemination) and is really 
advantageous than pregnancy diagnosis by rectal palpation, wherein $100 \%$ reliable results cannot be obtained at such an early stage. Bonato et al., (1990) and Boyd et al., (1990) reported higher accuracy around days 22-26 $(92 \%)$ and on day $20(100 \%)$, respectively. The absence of embryonic vesicle and its fluid are reliable signs of non-pregnancy (Pieterse et al., 1990). Contrarily, trans-rectal ultrasound scanning of cows on days 23, 28 and 35 post-service was less accurate than on day 42 (Hadiya et al., 2015). Similarly, as per the findings of Hadiya et al., (2015), day 3542 is the earliest possible time when pregnancy diagnosis should be attempted using ultrasound for maximum accuracy and specificity in zebu cattle.

Cows diagnosed pregnant on day 28 post A.I using ultrasound should be scheduled for a subsequent examination around day 60 post A.I, when the rate of embryonic loss per day decreases dramatically (Vasconcelos et al., 1997). Although the rate of pregnancy loss is significant in studies using ultrasound to assess the rate of loss, the technique of ultrasound itself has not been implicated as a cause of embryonic death in cattle (Ball and Logue, 1994; Baxter and Ward, 1997). Cows diagnosed pregnant at an early ultrasound examination have a greater risk of early embryonic loss and therefore, must undergo subsequent pregnancy examinations to identify and rebreed cows that experience such losses. If left unidentified, cows experiencing embryonic loss after an early pregnancy diagnosis would actually reduce reproductive efficiency by extending their calving interval (Frick, 2002).

\section{Re-examination for pregnancy on day 45}

All the animals which were found pregnant on day 28 post-insemination on the basis of embryonic heart beat were subjected to ultrasonographic re-examination on day 45 for embryonic viability. Out of 53 animals examined, 51 animals were having viable embryo with heart beat (Fig. 5). Out of these two animals which were observed with embryonic mortality one was heifer and second was >90days post-partum. Thus, incidence of EM in the current investigation was $3.77 \%$ (2/53). Again the beating of embryonic heart was considered as positive and confirmatory sign of pregnancy. Hence, two Hardhenu cows were confirmed nonpregnant on day 45 despite of being pregnant on day 28 post insemination. The images of embryo in gravid uterus were frozen and saved (Fig. 4a and 4b). The embryonic heart rate of 18 representative pregnant animals (Sahiwal, n=9; Hardhenu, n=9) were analyzed and the results are presented in Table 1.

It was observed that the embryonic heart rate was not significantly ( $\mathrm{p}>0.05)$ different between Sahiwal and Hardhenu cows at day 28 and day 45 . The values on day 28 were not significant as $\mathrm{p}=0.16$ and the values on day 45 were significant at $\mathrm{p}=0.08$ between Sahiwal and Hardhenu. However, there was significant $(p<0.05)$ increase in HR in both the groups of cows. The HR in pregnant Sahiwal cows increased significantly from $174.89 \pm 2.83$ (Day 28 ) to $185.44 \pm 3.16$ (Day 45). Whereas, in case of Hardhenu cows, it also increased significantly from $181.00 \pm 3.09$ (Day 28) to 195.11 \pm 4.08 (Day 45).

Fricke et al., (1998) reported that highest incidences $(13.5 \%)$ of early pregnancy loss occur during 28-56 days post insemination while Holness et al., (1977) reported 10\% embryonic mortality between 26 to 81 days after insemination in cows. In accordance to our results, Silke et al., (2002) using transrectal ultrasonography recorded the embryonic losses in cows and heifers between days 2842, 43-56, 57-70 and 71-84 as 3.2 and 1.52, 1.99 and 2.27, 0.66 and 1.51 and 1.34 and $0.76 \%$ respectively. 
Fig.1 Cytobrush with cytobrush assembly

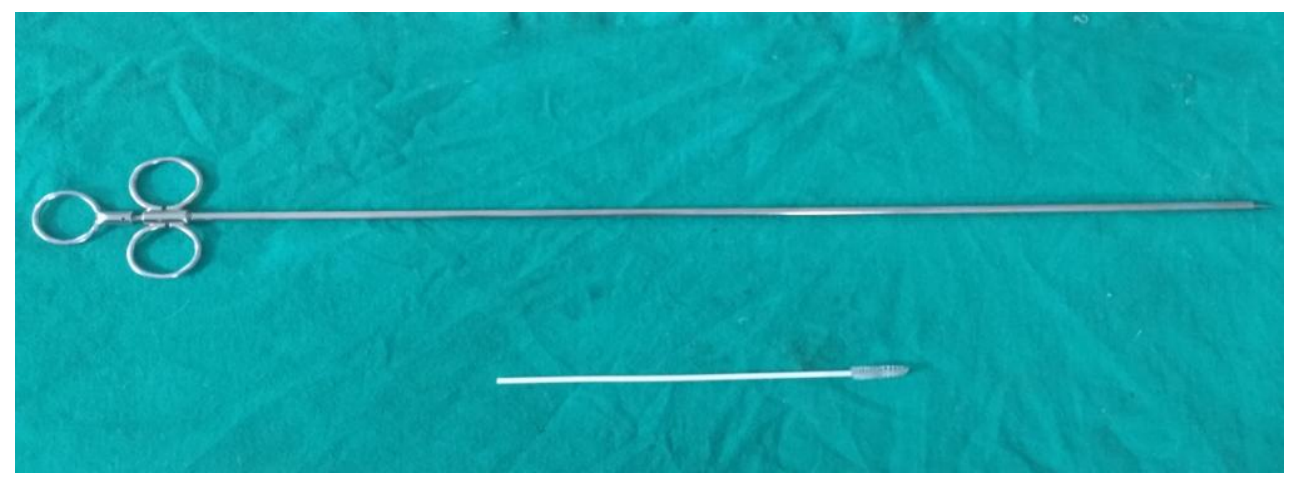

Fig.2a Amniotic vesicle in pregnant horn of Sahiwal cow at day 28

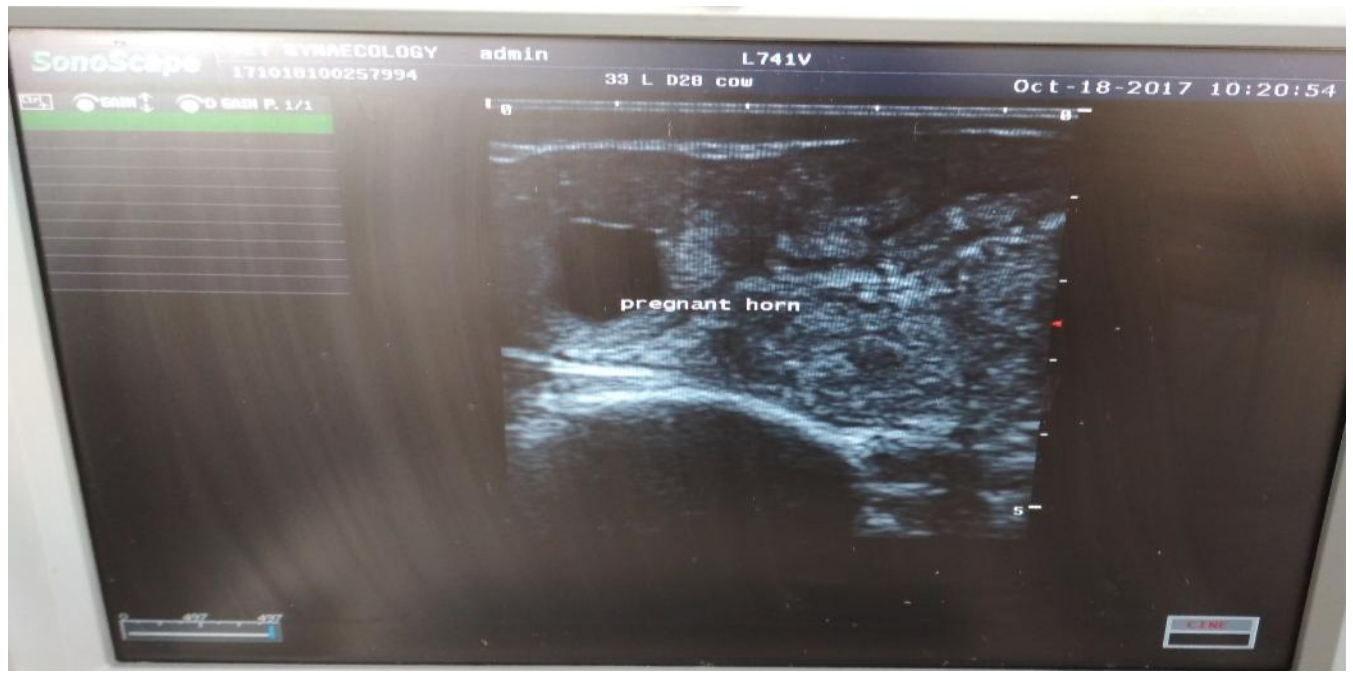

Fig.2b Amniotic vesicle in pregnant horn of Hardhenu cow at day 28

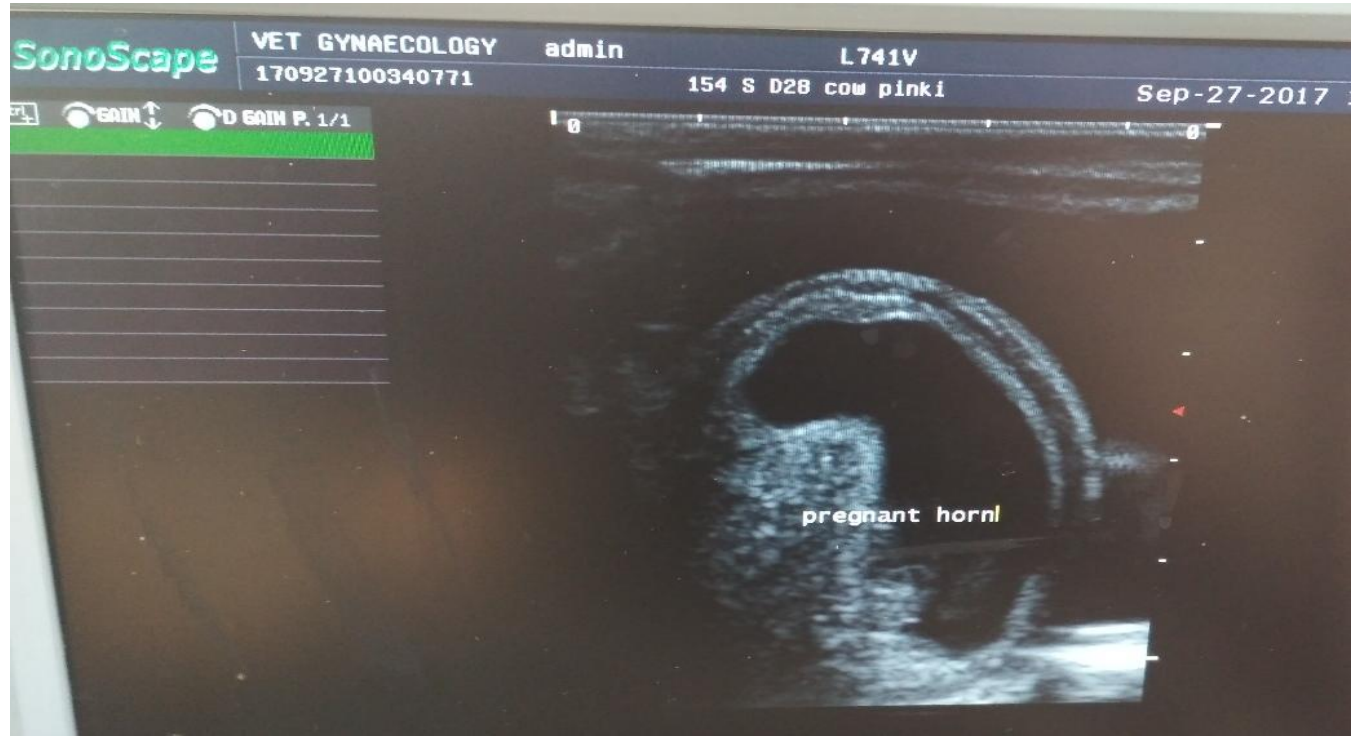


Fig.3 Embryonic heart beat on day 28

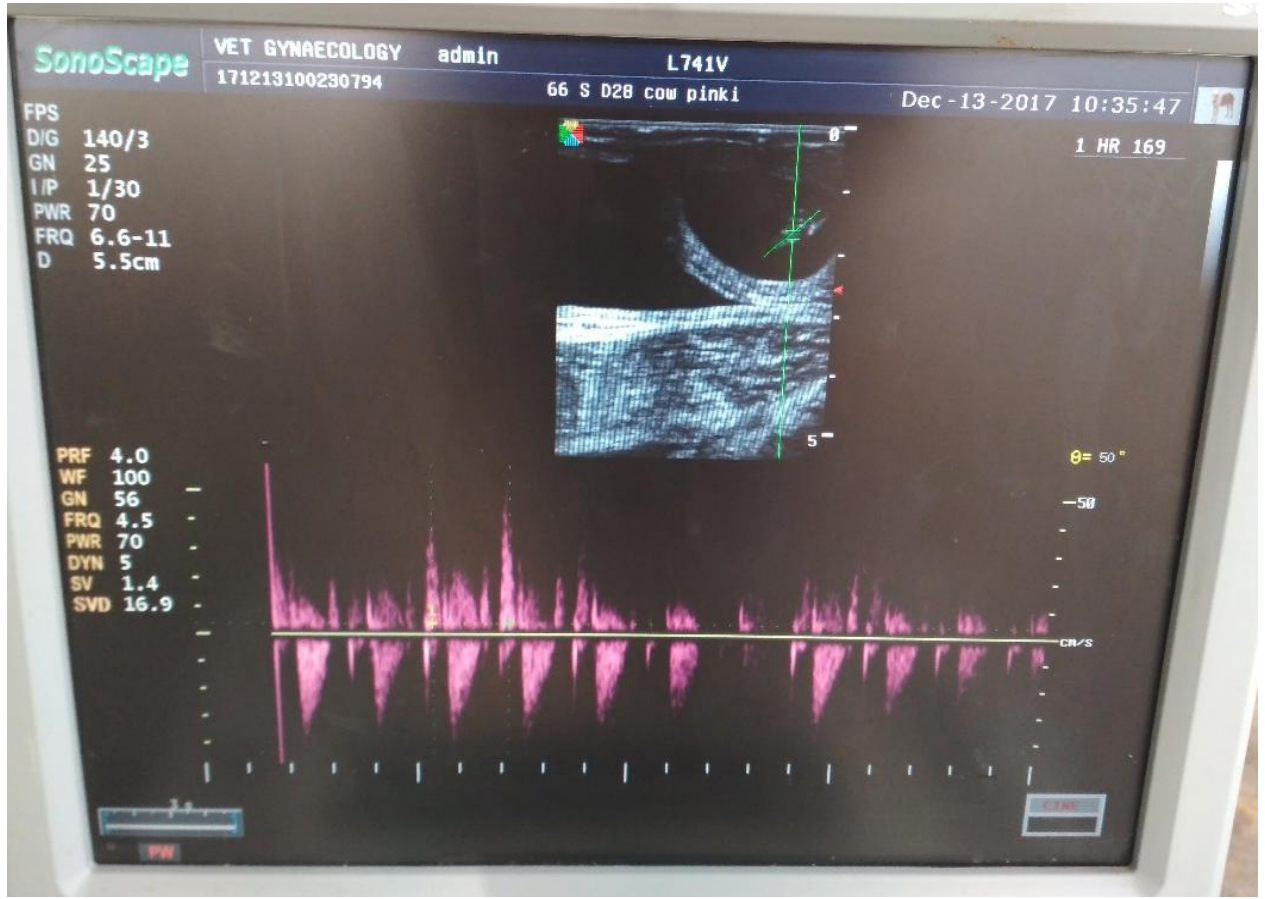

Fig.4a Developing embryo surrounded by chorioallantoic membrane in pregnant horn of Sahiwal cow on day 45

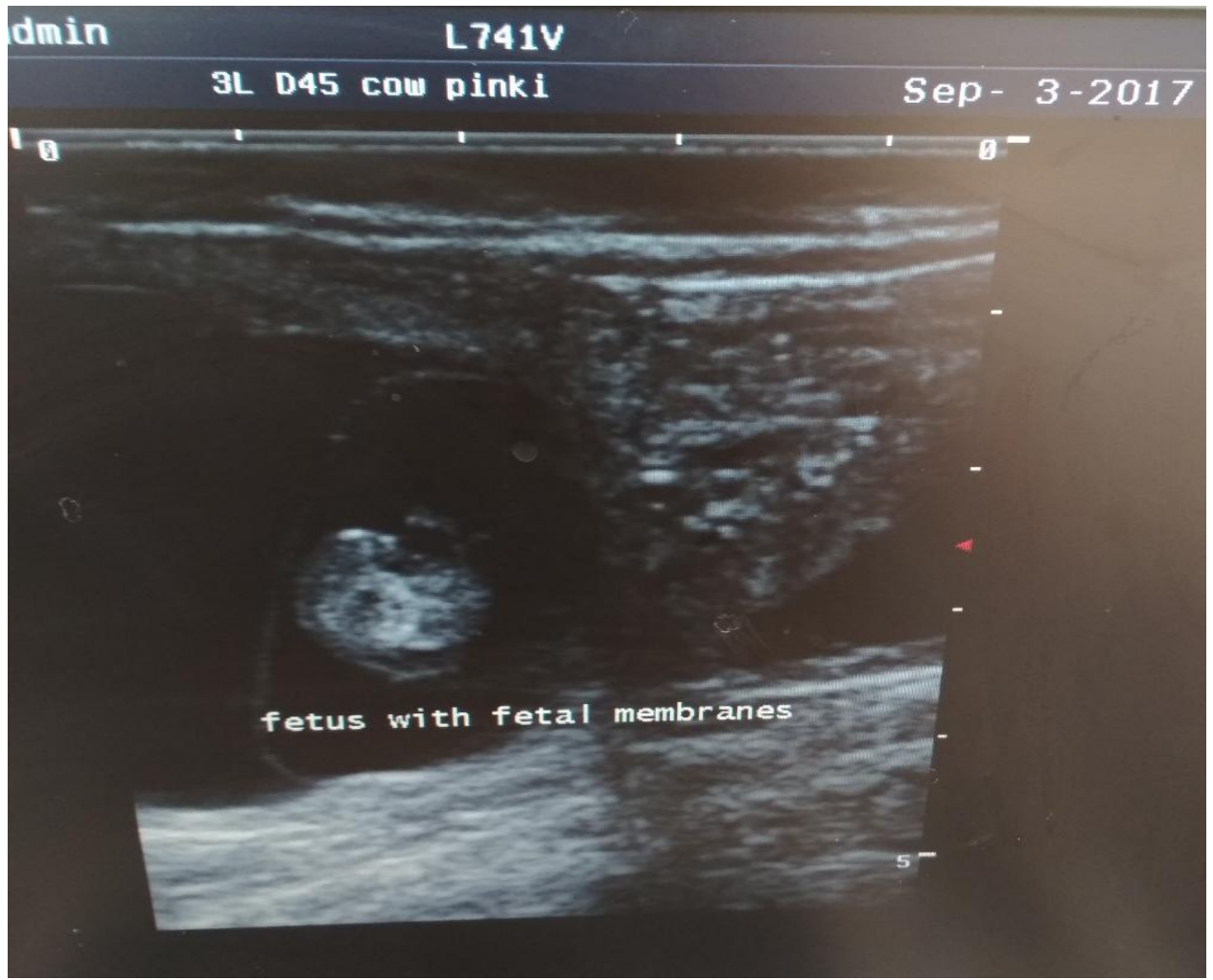


Fig.4b Developing embryo surrounded by chorioallantoic membrane in pregnant horn of Hardhenu cow on day 45

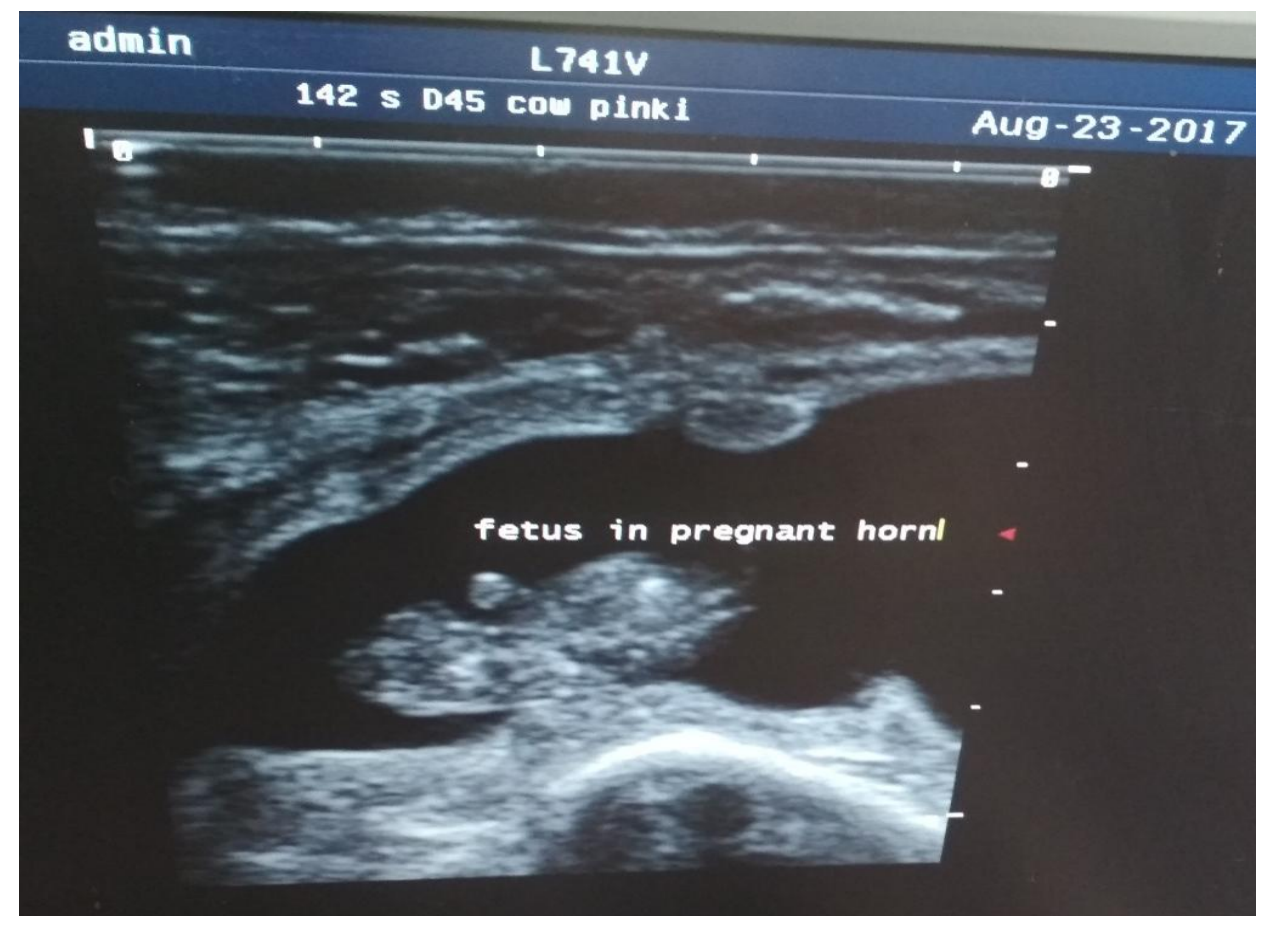

Fig.5 Embryonic heart beat on day 45

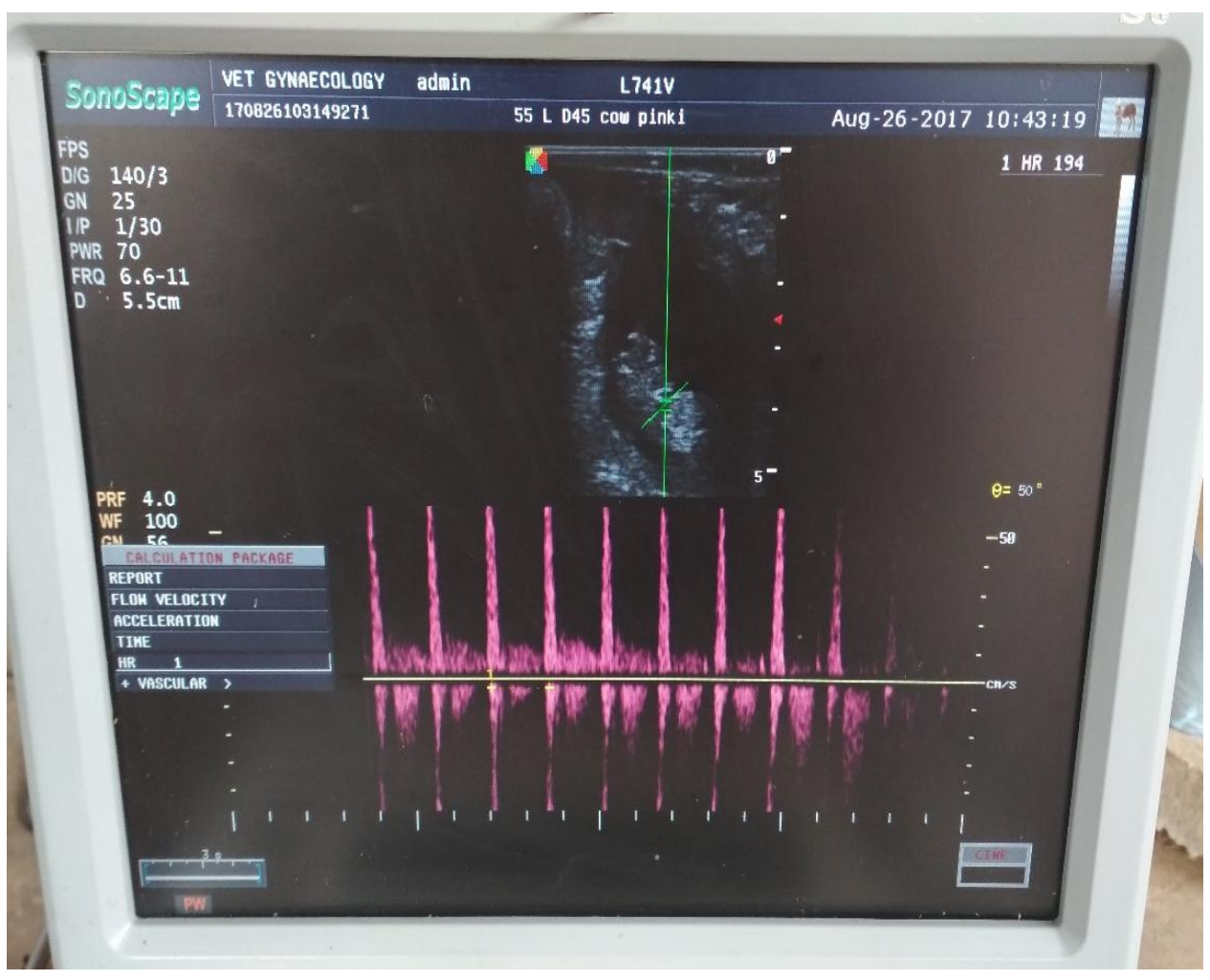


Fig.6 Polymorphonuclear cells and endometrial cells in animal No. 1 with embryonic mortality Field's staining 1000X

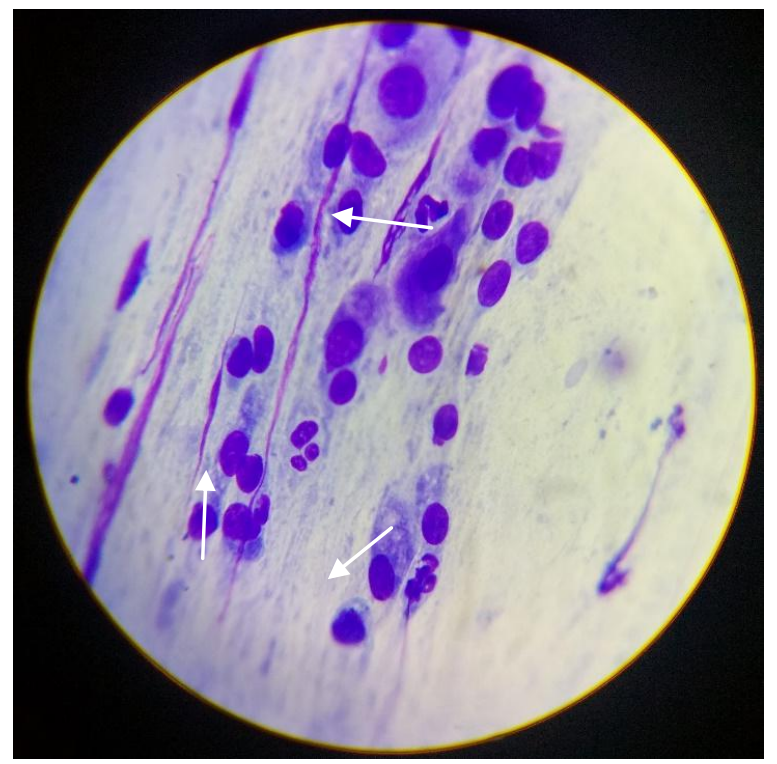

Fig.7 Polymorphonuclear cells and endometrial cells in animal No. 2 with embryonic mortality Field's staining 1000X

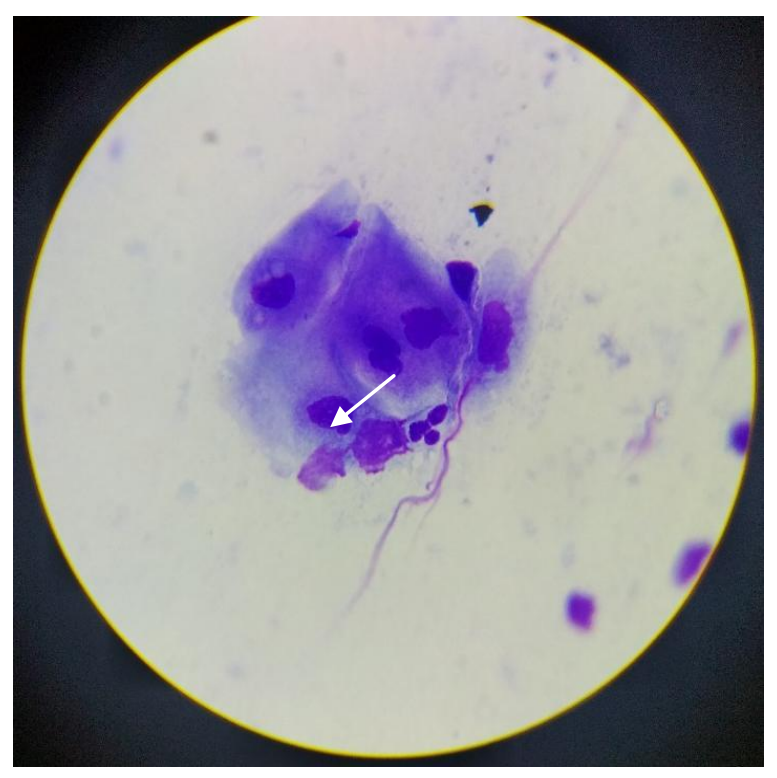

Table.1 Embryonic heart rate (Mean \pm SE) on day 28 and 45 post-insemination

\begin{tabular}{|l|c|c|}
\hline & Day 28 & Day 45 \\
\hline Sahiwal $(n=9)$ & $\mathbf{1 7 4 . 8 9} \pm \mathbf{2 . 8 3}$ & $\mathbf{1 8 5 . 4 4} \pm \mathbf{3 . 1 6}$ \\
\hline Hardhenu $(\mathrm{n}=9)$ & $\mathbf{1 8 1 . 0 0} \pm \mathbf{3 . 0 9}$ & $\mathbf{1 9 5 . 1 1} \pm \mathbf{4 . 0 8}$ \\
\hline Overall $(\mathrm{n}=18)$ & $\mathbf{1 7 7 . 9 4} \pm \mathbf{2 . 1 6}$ & $\mathbf{1 9 0 . 2 8} \pm \mathbf{2 . 7 7}$ \\
\hline
\end{tabular}

The means bearing different superscripts (x, y) differ significantly between days. 
Table.2 Microscopic count of polymorphonuclear cells (1000X)

\begin{tabular}{|c|c|c|}
\hline Sr. No. & Cattle No. & Polymorphonuclear cell count (\%) \\
\hline 1 & $139 \mathrm{~S}$ & 3 \\
\hline 2 & $105 \mathrm{~S}$ & 1 \\
\hline
\end{tabular}

Contrarily, Abdullah et al., (2014) and Whitlock and Maxwell (2008) using trans-rectal ultrasonography reported embryonic mortality rate as $7.69 \%$ (between day 30 to 45 ) and 5$10 \%$ (between day 28 to 42 days) respectively.

In the current investigation the embryonic heart beat rate on day 28 and 45 were recorded to be $177 \pm 2.16$ and $190.28 \pm 2.77$, respectively. The values in Sahiwal and Hardhenu breeds were non-significantly $(\mathrm{p}>0.05)$ different on day 28 $(177.89 \pm 2.83$ and $181.0 \pm 3.09)$ and 45 $(185.44 \pm 3.16$ and $195.11 \pm 4.08)$ within the days. Currans et al., (1986) in their study few days earlier than ours through trans-rectal ultrasonographic scanning on day 20.9 (19-24 days) post-insemination observed the embryo proper in HF cows with an average of $188 \pm 4.8$ beats/min. However, Singh et al., (2018) in Murrah buffaloes on day $26 \quad(163 \pm 6.03$ beats/min) and $46(181.33 \pm 4.16$ beats $/ \mathrm{min})$ recorded the slight lower embryonic heart rate. This may be due to species difference. Purohit (2010) opined that fetal heart beat can be seen between day 24-30 and the fetus itself between days 25-30 in most of the species. Totey et al., (1991) reported that the embryonic vesicle was first observable between days 18 and 20 whereas fetal heart beat was detectable by day 22.6 post breeding. This difference may either be due to experience of sonologist or species difference and in the current study the scheduled day of recording fell on day 28 postinsemination. Similar findings were also reported by Kastelic et al., (1988) starting at day 25 of pregnancy and recorded the heart beat between 140 to 160 beats per minute as twinkling light. In contrast to present study, Pawshe et al., (1994; 2011) observed buffalo fetal heart beat $(203.8 \pm 9.0 \mathrm{bpm})$ of the embryo on day $29.6 \pm 1.57$ and the heart rate further decreased to 150 beats per minute on day 62 .
The variations in fetal heart beat may be either due to species difference, external influences or expertise of the sonologist.

\section{Diagnosis of early embryonic mortality through cytobrush technique}

Endometrial samples were taken on day 45 post-insemination by using cytobrush technique from the two animals which suffered from embryonic mortality. The examination of slides under microscope at 100X and then under oil immersion (1000X magnification) by counting 100 cells to determine the percentage of polymorphonuclear cells that revealed presence of $<5 \%$ polymorphonuclear cells (Fig. 6 and 7 ) and Table 2. The samples sent to microbiology and Animal Biotechnology laboratory revealed absence of any kind of specific or non-specific infection as no microbial growth was observed on culture plates.

Cytobrush is a less harmful technique for the endometrium than the uterine lavage, since the fluid produces endometrial irritation (Brook, 1993). Prieto et al., (2012) observed that both uterine lavage and cytobrush are less invasive techniques than uterine biopsy (Kasimanickam et al., 2005). Saline solution also increases the time required to obtain samples, may cause a $17 \%$ of failure in attempts to recover fluid and increases the distortion of cells harvested by the lavage technique (Kasimanickam et al., 2005). Gilbert et al., (2005) in H.F cows at day 40-60 post-partum with $>5 \%$ neutrophils count considered as positive for sub-clinical endometritis and conception failure. Similarly, Singh et al., (2016) in cross bred cattle declared a cut off value 4\% PMN cell count at 90 days post-partum for sub-clinical endometritis. On the other hand, Kasimanickam et al., (2004) at 34-47 days post-partum in cows and Dutt et al., 
(2017) at 90 days postpartum in buffaloes with $>10 \%$ PMN cell count considered the animals positive for sub-clinical endometritis. In the present study, the two animals recorded with late embryonic mortality on day 45 had viable embryo on day 28 , so the probability of subclinical endometritis is straightway rejected.

Since the PMN cell count in the current study was $<3 \%$ and no microbial growth was observed on culture plates, therefore the embryonic mortality was rather due to hormonal or some other factors. Hence, $\leq 3 \%$ PMN cell count may be considered as normal (unreported). Secondly, incidence of embryonic mortality in the current investigation recorded was $3.77 \%$ (2/53). Thirdly, the early pregnancy diagnosis carried out on day 28 postinsemination should also be re-evaluated for diagnosis of embryonic mortality on day 45 post-insemination.

\section{References}

Abdullah, M., Mohanty, T.K., Kumaresan, A., Mohanty, A.K., Madkar, A.R., Baithalu, R.K. and Bhakat, M. (2014). Early pregnancy diagnosis in dairy cattle: economic importance and accuracy of ultrasonography. Adv. Anim. Vet. Sci., 2(8): 464-467.

Bajaj, N.K. and Sharma, N. (2011). Endocrine causes of early embryonic death. An Overview. Current Research in Dairy Sci., 3(1): 1-24.

Bajaj. N.K. (2001). Effects of herbal medication on endometritis in buffaloes. M.Sc. Thesis, Gujarat Agriculture University, Anand Campus, S.K. Nagar (Gujarat), India.

Balhara, A.K., Gupta, M., Singh, S., Mohanty, A.K. and Singh, I. (2013). Early pregnancy diagnosis in bovines: current status and future directions. Sci. World J., 2013: 1-10.

Ball, P.J.H. and Logue, D.D.N. (1994). Ultrasound diagnosis of pregnancy in cattle. Vet. Rec., 134: 532.
Baxter, S. J. and Ward, W.R. (1997). Incidence of fetal loss in dairy cattle after pregnancy diagnosis using an ultrasound scanner. Vet. Rec., 140: 287-288.

Beal, W.E., Perry, R.C., Corah, L.R., (1992). The use of ultrasound in monitoring reproductive physiology of beef cattle. $J$. Anim. Sci., 70: 924-929.

Bekele, N., Addis, M., Abdela, N. and Ahmed, W.M. (2016). Pregnancy diagnosis in cattle for fertility management. Glob. Vet., 16(4): 355-364.

Bonato, O., Fiocca, A., Pigato, M. and Scorzato, I. (1990). Early diagnosis of pregnancy by ecography in cattle. Praxis Veterinaria (Milano), 11(2): 18-20.

Boyd, J.S., Omran, S.N. and Ayliffe, T.R. (1990). Evaluation of real-time B-mode ultrasound scanning for detecting early pregnancy in cows. Vet. Rec., 127: 350352.

Brook, D. (1993). Uterine cytology. In: McKinnon AO, Voss JL, eds. Equine Reproduction. $2^{\text {nd }}$ edn. London. Lea and Febiger, 246-254

Campanile, G.N. (2007). Embryonic mortality in cows. Italian J. Anim. Sci., 6(2): 119129.

Chaudhary, A.K. and Purohit, G.N. (2012). Ultrasonographic detection of early pregnancy loss in dairy cows. J. Animal Sci. Adv., 8: 706-710.

Committee on Reproductive Nomenclature (1972). Recommendations for standardizing bovine reproductive terms. Cornell. Vet., 62: 216-237.

Curran, S., Pierson, R.A. and Ginther, O.J. (1986). Ultrasonographic appearance of the bovine conceptus from days 20 through 60. Journal of the American Veterinary Medical Association, 189(10): 1295-1302.

Diskin, M.G. and Morris, D.G. (2008). Embryonic and early fetal losses in cattle and other ruminants. Reprod. Domest. Anim., 43(2): 260-267.

Dutt, R., Singh, G., Singh, M., Sharma, M., Dalal, J. and Chandolia. R.K. (2017). Diagnosis of subclinical endometritis in 
Murrah buffaloes through cytobrush technique. International Journal of Current Microbiology and Applied Sciences. 6 (11): 494-499.

FAO (1994). Production Year Book Food. Food and Agriculture Organization of the United Nations, Rome, Italy. p 336.

Fricke, P.M. (2002). Scanning the future: Ultrasonography as a reproductive management tool for dairy cattle. J. Dairy Sci., 85(8): 1918-1926.

Fricke, P.M., Guenther, J.N. and Wiltbank, M.C. (1998). Efficacy of decreasing the dose of GnRH used in a protocol for synchronization of ovulation and timed AI in lactating dairy cows. Theriogenology. 50: 1275-1284.

Gilbert, R.O., Shin, S.T., Guard, C.L., Erb, H.N. and Frajblat, M. (2005). Prevalence of endometritis and its effects on reproductive performance of dairy cattle. Theriogenology. 64: 1879-1888.

Hadiya, K.K., Dhami, A.J., Nakrani, B.B., Patel, J.A. and Sarvaiya, N.P. (2015). Predictive efficiency of USG and plasma progesterone assay for detection of early pregnancy and embryonic mortality in cattle. G.J.B.B., 4(1): 277-281.

Hansela, W., Spaldinga, R.W., Larson, L.L., Laster, D.B., Wagner, J.F. and Braun, R.K. (1976). Influence of human chorionic gonadotropin on pregnancy rates in the lactating dairy cows. J. Dairy Sci., 59: 751-754.

Holness, D.H., Ellison, J.A. and Willum's, L.M. (1977). Conception of beef cows in relation to concentration of progesterone in peripheral blood. Anim. Breed. Abs., 46(5): 2070.

Kasimanickam, R., Duffield, T.F., Foster, R.A., Gartely, C.J., Leslie, K.E., Walton, J.S. and Johnson, W.H. (2004). Endometrial cytology and ultrasonography for detection of sub-clinical endometritis in postpartum dairy cattle. Theriogenology. 62: 9-23.

Kasimanickam, R., Duffield, T.F., Foster, R.A., Gartley, C.J., Leslie, K.E., Walton, J.S. and Johnson, W.H. (2005). A comparison of the cytobrush and uterine lavage techniques to evaluate endometrial cytology in clinically normal postpartum dairy cows. Can Vet J., 46: 255-259.

Kastelic, F.J., Northey, D.L. and Ginther, O.J. (1991). Spontaneous embryonic death on days 20 to 40 in heifers. Theriogenology. 35: 351-363.

Kastelic, J.P., Curran, S., Pierson, R.A. and Ginther, O.J. (1988). Ultrasonic evaluation of the bovine conceptus. Theriogenology. 29(1): 39-54.

Maurer, R.R. and Chenault, J.R. (1983). Fertilization failure and embryonic mortality in parous and non-parous beef cattle. J. Anim. Sci., 56: 1186-1189.

Pawshe, C.H., Appa Rao, K.B. and Totey, S.M. (1994). Ultrasonographic imaging to monitor early pregnancy and embryonic development in the buffalo (Bubalus bubalis). Theriogenology. 41(3): 697-709.

Pawshe, C.H., Patil, S.R. and Ingwale, M.V. (2011). Ultrasonography- a diagnostic tool for detection of early pregnancy and study of embryonic development in the buffalo and cattle. Intas Polivet. 12(1): 14.

Pierson, R.A. and Ginther, O.J. (1984) Ultrasonography for detection of pregnancy and study of embryonic development in heifers. Theriogenology. 22(2): 225-233.

Pieterse, M.C., Szenci, O., Willemse, A.H., Bajcsy, C.S.A., Dieleman, S.J. and Taverne, M.A.M. (1990). Early pregnancy diagnosis in cattle by means of linear array real-time ultrasound scanning of uterus and a qualitative and quantitative milk progesterone test. Theriogenology. 33: 697-707.

Prieto, M., Barrio, M., Quintela, L.A., PerezMartin, C.C., Becerra, J.J., Vigo, M., Diaz, C., Cainzos, J., Prieto, A., Fernandez, F.I., Martinez, D. and Herradon, P.G. (2012). Validation of simple method for the interpretation of uterine cytology in cows. Vet. Med., 57: 360-363. 
Prvanovic, N., Tomaskovic, A., Grizelj, J., Kocila, P. and Samardzija, M. (2009). Monitoring of early pregnancy and early embryonic mortality by ultrasound and determination of pregnancy-associated glycoproteins and progesterone in cows. Vet. Arhiv., 79: 259-267.

Purohit, G.N. (2010). Methods of pregnancy diagnosis in domestic animals: The Current Status. Webmed. Central Reproduction. 1(12): 1-28.

Roche, J.F., Bolandl, M.P. and McGeady, T.A. (1981). Reproductive wastage following AI of heifers. Vet. Rec., 109: 401-404.

Romano, J.E., Thompson, J.A. and Kraemer, D.C. (2006). Early Pregnancy Diagnosis by trans-rectal ultrasonography in dairy cattle. Theriogenology. 66(4): 1034-1041.

Silke, V., Diskin, M.G., Kenny, D.A., Boland, M.P., Dillon, P., Mee, J.F. and Sreenan, J.M. (2002). Extent, pattern and factors associated with late embryonic loss in dairy cows. Anim. Reprod. Sci., 71: 1-12.

Singh, G., Chandolia, R.K., Dutt, R., Dalal, J. and Saini, A. (2018). Two dimensional trans-rectal ultrasonographic studies in early pregnant Murrah buffaloes. Indian J. Anim. Sci., 88(1): 59-64.

Singh, J., Honparkhe1, M., Chandra, M., Kumar, A., Ghuman, S.P.S. and Dhindsa, S.S. (2016). Diagnostic efficacy of uterine cytobrush technique for subclinical endometritis in crossbred dairy cattle. Indian Vet. J., 93 (2): 11-13.
Sreenan, J. and Diskin, M. (1986). The extent and timing of embryonic mortality in the cow. In: embryonic mortality in farm animals, Sreenan, J. and Diskin, M. (Eds.). Martinus Nijhoff Publishers, Amsterdam, p.p: 1-11.

Stronge, A.J.H., Sreenan, J.M., Diskin, M.G., Mee, J.F., Kenny, D.A and Moris, D.G. (2005). Post-insemination milk progesterone concentration and embryo survival in dairy cows. Theriogenology. 64: 1212-1224.

Totey, S.M., Singh, G., Taneja, M. and Talwar, G.P. (1991). Ultrasonography for detection of early pregnancy following embryo transfer in unknown breeds of Bos indicus cows. Theriogenology. 35: 487-497.

Vasconcelos, J.L.M., Silcox, R.W., Lacerda, J.A., Pursley, J.R. and Wiltbank M.C. (1997). Pregnancy rate, pregnancy loss, and response to heat stress after AI at two different times from ovulation in dairy cows. Biol. Reprod., 56 (1): 140.

Whitlock, B.K. and Maxwell, H.S. (2008). Pregnancy-associated glycoproteins and pregnancy wastage in cattle. Theriogenology. 70: 550-559.

Zavy, M.T. (1994). Embryonic Mortality in Cattle. In: Embryonic Mortality in Domestic Species, Zavy, M.T. and Geisert, R.D. (Eds.). CRC Press, Boca Raton, pp: 99-140.

\section{How to cite this article:}

Pinki Rani, R.K. Chandolia, Ravi Dutt, Nitin Soni, S.S. Dhaka, Sandeep Kumar, A.K. Pandey and Gyan Singh. 2018. Ultrasonographic Assessment of Embryonic Mortality in Cows. Int.J.Curr.Microbiol.App.Sci. 7(06): 387-399. doi: https://doi.org/10.20546/ijcmas.2018.706.044 